|| Print ISSN: 2589-7837 || Online ISSN: 2581-3935 ||

International Journal of Medical Science and Diagnosis Research (IJMSDR)

Available Online at www.ijmsdr.com

NLM (National Library of Medicine ID: 101738824)

Original Research Article

Volume 6, Issue 2; February: 2022; Page No. 09-11

\title{
Role of Gentamicin Loaded Collagen on Compound Fracture Internal Fixation
}

\author{
Nitin Sanadhya ${ }^{1}$ \\ ${ }^{1}$ Assistant Professor, Department of Orthopaedics, Geetanjali Medical College and \\ Hospital, Udaipur, India.
}

Conflicts of Interest: Nil

Corresponding author: Nitin Sanadhya

DOI: https://doi.org/10.32553/ijmsdr.v6i2.919

\begin{abstract}
:
Introduction: In the today's world with faster ways of transportation high velocity accidents and the compound fracture are increasing day by day producing a challenge preventing post operative wound infections after internal fixation of fracture.

Materials and Methods: 50 patients of compound fractures were included in the study and were randomly divided in 2 groups of 25 each. Both the groups undergone internal fixation with stainless steel implant and one group wound is closed with gentamicin loaded collagen in it and other group without it

Method: In both the groups same process of and lavage is used and fractures were fixed internally fixed. A group has 25 patients in which after internal fixation the gentamicin loaded collagen is placed inside and in B group after internal fixation wound is closed without gentamicin loaded collagen.

Results: In group A where Gentamicin loaded collagen was placed wound infection was there in 2 patients. In Group B were no gentamicin loaded collagen was used 9 patietns has infections. P value 0.0275
\end{abstract}

Discussion: After surgery wound is assessed for post operative infection on 2 nd post op day 14 day at 4 weeks 6 weeks 3 months and 6 months

Conclusion: The Author believe that use of gentamicin loaded collagen significantly reducing the chance of infection in compound fractures surgeries.

Keywords: compound fracture, gentamicin loaded collagen, post operative infection

\section{Introduction:}

In the todays world as the traffic and transportation is getting fast day by day the frequency of compound fractures is increasing and is looking at the rate with traffic is getting busy the load of compound fractures will be in raising trend in future as well. And accordingly the compound fracture fixation will increase in which there is a potential chance of infection is there in every case which is nightmare for any orthopaedic surgeon. Even after a thorough debridement and lavage changes of infection are very high. So present study is to evaluate the effect of gentamicin loaded collagen on post operative infections in compound fracture internal fixation

\section{Materials and Methods}

This prospective study included 50 fresh cases compound Grade 3A fracture presented within $6 \mathrm{hrs}$ of sustaining injury during the period from jan 2021 to june 2021,. All fracture had 
occurred due to RTA .The study was conducted after ethical committee clearence of the institution. Informed written consent was taken from all the patients. The fracture was classified accourding to Gustilo Anderson . Patients were excluded from the study if they were found a) unfit for anesthesia, b) patients refused consent, c) polytrauma, d) head injury, e) immuno compromised patients, f) pathological fractures.

All the compound fractures were thoroughly debrided and lavage was done with saline and internally fixed after that in Group A patients gentamicin loaded collagen was placed inside the wound and in Group B noting is placed and wound is closed in layers. Dressing was done on 2 nd post op day , 7 the day , 14 day stitch were removed, patient was follow up at 4 weeks and 6 weeks. 3 months and 6 months and were looked for wound infection in all the visits.

\section{Results}

The present study included total 50 cases ,25 in group A cases and 25 in group B.All cases were followed up 6 months. No case was lost to follow-up In follow up Dressing the 2nd post op day 7 th post operative day , 14 th post operative day, 4 weeks , 6 weeks 3 month, and till 6 months after procedure and look for infection out of which 2 patients shows infection in group $\mathrm{A}$ and 9 patients shows infections in group B.

Table 1:

\begin{tabular}{|l|l|l|l|}
\hline & cases & Control & \\
\hline Exposed(genta/collagen) & 2 & 23 & 25 \\
\hline Unexposed & 9 & 16 & 25 \\
\hline & 12 & 38 & 50 \\
\hline
\end{tabular}

Odds ratio $=0.1546$

$95 \% \mathrm{CI}=0.0294$ to 0.8128 ( $\mathrm{CI}=$ confidence interval)

$\mathrm{P}$ value is $=0.0275$

\section{Discussion}

In our study the infection rate in comparison groups is 4.5 times higher in cases where gentamicin loaded collagen was not used.

Our results are compariable to susheel chaudhary et al (1) who has significant reduction in infection rate in compound factures, but in comparision to Westberg et al (3)who do not have significant difference between the two groups may be because they are using it in joint surgeries . Susan et al(2) didn't find any difference between two groups and their results differ from us .Morgenstern et al(4) has similar results comparable to ours.

The limitation of present study is the short duration of follow up. There is scope for improvement in results as well as increase in complications with a longer follow up.

\section{Conclusion}

Use of gentamicin loaded collagen is significantly reducing the chance of infection in compound fractures surgeries with $p$ value of 0.0275 . And hence the chances of resurgery due to infection.

\section{References}

1. Chaudhary S, Sen RK, Saini UC, Soni A, Gahlot N, Singh D. Use of gentamicinloaded collagen sponge in internal fixation of open fractures. Chin J Traumatol. 2011;14(4):209-14. PMID: 21801664.

2. Ge, Susan M. MD; Harvey, Edward J. MD* Collagen fleece in orthopaedic infections, OTA International: June 2021 Volume 4 - Issue 3S - p e111

3. Marianne Westberg, Frede Frihagen, OleChristian Brun, Wender Figved, Bjarne 
Grøgaard, Haldor Valland, Helge Wangen, Finnur Snorrason, Effectiveness of Gentamicin-Containing Collagen Sponges for Prevention of Surgical Site Infection After Hip Arthroplasty: A Multicenter Randomized Trial, Clinical Infectious Diseases, Volume 60, Issue 12, 15 June 2015, Pages 1752-1759,
4. Morgenstern M, Vallejo A, McNally MA, Moriarty TF, Ferguson JY, Nijs S, Metsemakers WJ. The effect of local antibiotic prophylaxis when treating open limb fractures: A systematic review and meta-analysis. Bone Joint Res. 2018 Aug 4;7(7):447-456. 